\title{
Urinary antimony in infancy
}

Carol Dezateux, H Trevor Delves, Janet Stocks, Angela Wade, Liane Pilgrim, Kate Costeloe

\begin{abstract}
Objective-To determine whether antimony may be detected in the urine during infancy and early childhood and its association with passive exposure to tobacco smoke, as assessed by urinary cotinine.

Design-Analysis of spare aliquots of urine collected from infants participating in studies of respiratory function and passive smoking. Urinary antimony was assayed using inductively coupled plasma mass spectroscopy in 201 urine specimens collected at different ages throughout the first two years of life from 122 term and 26 preterm infants. Urinary cotinine was measured using gas liquid chromatography.

Main outcome measure-Urinary antimony concentrations.

Results-Absolute antimony concentrations varied widely between infants, being below the laboratory detection limit of $0.02 \mu \mathrm{g} / 1$ in $7 \%$ of samples, below $0.5 \mu \mathrm{g} / 1$ in $90.5 \%$, and above the reference value of $1 \mu \mathrm{g} / \mathrm{l}$ reported for non-occupationally exposed UK populations in $4 \%$. Creatinine standardised antimony values were unrelated to postnatal age or urinary cotinine concentrations and were highest in urine collected from preterm infants within 24 hours of birth (geometric mean (95\% confidence interval): $2.3 \mathrm{ng} / \mathrm{mg}$ (1.5 to 3.4$)$ ). Conclusion-Although antimony is present at very low concentrations in urine during infancy and early childhood, the relevance to health is uncertain. The higher levels found in preterm infants may reflect prematurity or fetal assimilation of antimony. Tobacco is unlikely to be an important source of environmental exposure to antimony during infancy and early childhood.
\end{abstract}

(Arch Dis Child 1997;76:432-436)

Anaesthesia, Intensive Therapy and

Respiratory Medicine, Institute of Child

Health, London

J Stocks

L Pilgrim

Academic Department of Child Health, St

Bartholomew's and the Royal London School

of Medicine and

Dentistry, London

K Costeloe

Correspondence to:

Dr Dezateux.

Accepted 6 January 1997 the uptake and excretion of antimony in infants and its relation to potential environmental sources such as tobacco smoke. ${ }^{11}$ Although antimony may accumulate gradually in organs such as the lungs and liver, studies in adults suggest that the half life of renal elimination of both trivalent and pentavalent forms of antimony is approximately four days. ${ }^{12-14}$ In view of this, and the acceptability and relative simplicity of urine collection in healthy infants and young children, measurement of urinary antimony may be a useful means of assessing environmental exposure to antimony at this age. The aim of this study was to determine whether antimony could be detected in the urine during infancy and early childhood by analysing spare aliquots of urine originally collected for cotinine assay from healthy term and preterm infants and those with prior wheezing. A subsidiary aim was to examine whether the concentrations of urinary antimony observed were associated with passive exposure to tobacco smoking, as assessed by urinary cotinine.

\section{Methods}

STUDY POPULATION

The study population comprised infants participating in three ongoing studies of infant respiratory function, ${ }^{15-17}$ from whom urine specimens were collected for cotinine assay ${ }^{18}$ at the time of respiratory function testing. In the first study, ${ }^{15}$ urine was collected on two occasions from healthy term infants recruited from the community shortly after birth: at approximately 8 weeks (before any lower respiratory tract illness (LRI) or wheezing) and at 1 year of age. In the second study, ${ }^{16}$ urine was collected, on one occasion only, from infants with prior physician diagnosed LRI with wheeze. In the third study, ${ }^{17}$ urine was collected within the first 24 hours of life from healthy preterm ( $<37$ weeks) infants admitted to a special care baby unit. All except the preterm infants were sedated with triclofos sodium (100 $\mathrm{mg} / \mathrm{kg}$ ) by mouth for respiratory function testing, ${ }^{19}$ usually given within the half hour preceding urine collection.

Spare aliquots of urine were available for antimony assay for 148 infants ( 80 boys). For the purposes of this study, infants were allocated to one of four groups according to age and status at the time of lung function testing. Group 1 comprised 26 healthy preterm newborn infants; group 2 were 74 healthy full term infants tested at approximately 8 weeks of age; group 3 consisted of 58 healthy full term infants tested at approximately 1 year of age; and group 4 were 43 infants with prior physician diagnosed LRI with wheeze. As urine was obtained from healthy term infants on two occasions, 35 infants in group 3 and 18 of those 
in group 4 had been previously tested at 8 weeks of age and were therefore included in group 2. However, groups 3 and 4 were mutually exclusive.

For each infant, details of maternal smoking during pregnancy, postnatal exposure to smoking from maternal, household, and other sources, and other medical and social factors were obtained from the parents at recruitment and subsequently. At each test, parents were asked for details of any medication given to the infant (both prescribed and other), and whether their infant had been exposed to any tobacco smoke in the preceding 24 hours. These studies received prior approval from the ethics committee of the Great Ormond Street NHS Trust, who subsequently granted permission to analyse spare aliquots of urine for antimony.

URINE COLLECTION AND ANALYSIS

Urine was collected using self adhesive plastic bags (Dover, Sherwood Medical) applied to the infant's perineum, transferred using $10 \mathrm{ml}$ plastic syringes (Becton-Dickinson) into $5 \mathrm{ml}$ screw capped tubes (Griffiths-Nielson), and frozen at $-20^{\circ} \mathrm{C}$ within two hours of voiding. When more than $5 \mathrm{ml}$ was obtained, two separate aliquots were frozen, the first of which was assayed for cotinine using gas liquid chromatography ${ }^{18}$ at the National Poisons Unit at New Cross Hospital. Antimony analysis of the remainder of the refrozen first aliquot and/or the previously unsampled second aliquot was performed using inductively coupled plasma mass spectroscopy by the Department of Clinical Biochemistry at Southampton General Hospital, where creatinine assays were also undertaken. Antimony and cotinine were analysed with the laboratories blinded to the status of the infant. A prior in vitro study, undertaken to determine the potential for antimony contamination of urine samples during collection, imparted mean (SD) blank concentrations of $0.004(0.004) \mu \mathrm{g} / 1$. This indicated that urine collected for these studies could be used to provide reliable estimates of antimony.

A standard model Perkin-Elmer/Sciex 5000 inductively coupled plasma mass spectrometer (Perkin-Elmer-Sciex Inc, Toronto, Ontario, Canada) was used to measure antimony in the urine. Each specimen was analysed in duplicate and prepared for analysis by aqueous dilution of $200 \mu \mathrm{l}$ volumes and with the addition of indium as an internal standard. Matrix matched standards were used for calibration and prepared by addition of $0,0.25,0.50,1.0$, $2.0,5.0$ and $10.0 \mu \mathrm{g} / 1$ to urine from nonsmoking adults. The calibration curves were linear from this range and all data points showed good proximity to the regression lines - that is, $r^{2}$ ranged over 0.9990 to 0.9999 for 10 calibration curves over a five month period. A stringent internal quality control (IQC) procedure was employed. The matrix matched standards were analysed as IQC samples with each analytical run at a mean frequency of approximately one per 10 urine samples. The mean recovery of antimony added to the seven IQC urines was $98 \%$ with the following regression equation: $\mathrm{y}=0.98 \mathrm{x}+$ $0.06 \mu \mathrm{g} / 1\left(r^{2}=0.99997\right)$. As further tests of the validity of the observed antimony concentrations, 417 repeated analyses were carried out, blinded, on 130 urine specimens, with up to four repeats per specimen. It was found that $90 \%$ of the individual analyses differed by less than $0.1 \mu \mathrm{g} / 1$ from the mean, and $97 \%$ by less than $0.2 \mu \mathrm{g} / 1$. Detection limits $(3 \times \mathrm{SD}$ of replicate blank measurements) were $0.004 \mu \mathrm{g} / \mathrm{l}$ using $4.0 \mathrm{ml}$ volumes of urine with minimal dilution, and $0.02 \mu \mathrm{g} / 1 \mathrm{using} 200 \mu \mathrm{l}$ volumes of urine with $(1+14)$ dilutions. Values below this limit were assigned a value of $0.0001 \mu \mathrm{g} / 1$ when creatinine standardised values were calculated.

\section{DATA HANDLING AND STATISTICAL ANALYSIS}

Absolute antimony $(\mu \mathrm{g} / \mathrm{l})$ and creatinine standardised antimony ( $\mathrm{ng} / \mathrm{mg}$ creatinine) and cotinine (ng/mg creatinine) were log normally distributed and reported as the geometric mean and $95 \%$ confidence interval (CI) for each group. A random effects model was used to estimate the proportion of the variability in the log transformed creatinine standardised antimony attributable to differences between replicates, between infants and between aliquot type-that is, whether previously sampled for cotinine analysis or not, using the SAS VARCOMP procedure (SAS Version 6.09). Repeat observations within each child on any one occasion were combined for subsequent analyses. For the subgroup of infants with two measurements, the mean within-subject change in creatinine standardised antimony was presented, together with the $95 \% \mathrm{CI}$, and examined using a one sample $t$ test.

Table 1 Background characteristics of infants. Data are expressed as median (interquartile range) unless otherwise stated

\begin{tabular}{lllll}
\hline & $\begin{array}{c}\text { Group 1 (healthy } \\
\text { preterm) }(n=26)\end{array}$ & $\begin{array}{l}\text { Group 2 (healthy } \\
\text { younger term) }(n=74)\end{array}$ & $\begin{array}{l}\text { Group 3 (healthy } \\
\text { older term) }(n=58)\end{array}$ & $\begin{array}{l}\text { Group 4 (prior } \\
\text { wheezing) }(n=43)\end{array}$ \\
\hline Boys (\%) & 42 & 57 & 47 & 65 \\
Age at test (weeks) & $0.1(0.1-0.1)$ & $8.0(7.1-8.7)$ & $54.5(52.7-56.9)$ & $55.1(48.5-61.2)$ \\
Body weight at test (kg) & $1.9(1.6-2.1)$ & $4.9(4.6-5.4)$ & $9.8(9.2-10.4)$ & $9.8(8.2-10.7)$ \\
Crown-heel length at test (cm) & $\mathrm{NA}$ & $58.1(56.6-59.6)$ & $77.3(76.2-79.4)$ & $76.6(73.7-79.8)$ \\
Birth weight (g) & $1900(1600-2100)$ & $3400(3000-3700)$ & $3500(3300-3900)$ & $3200(2800-3500)$ \\
Gestation (weeks) & $34(31-35)$ & $40(39-41)$ & $40(40-41)$ & $39(38-40)$ \\
Mothers who smoked during pregnancy (\%) & 15 & 42 & 34 & 56 \\
In 24 hours preceding urine collection: & & & & 68 \\
$\quad$ Infants exposed to tobacco smoke (\%) & $15^{\star}$ & 61 & 54 & 18 \\
$\quad$ Infants on medication (\%) & 0 & 14 & 20 & \\
\hline
\end{tabular}

$\mathrm{NA}=$ not available

* For preterm infants, $\%$ of mothers who smoked during pregnancy. 
Table 2 Antimony and cotinine values according to infant status. Data expressed as geometric mean (95\% CI) unless otherwise stated

\begin{tabular}{|c|c|c|c|c|}
\hline & $\begin{array}{l}\text { Group } 1 \text { (healthy } \\
\text { preterm) }(n=26)\end{array}$ & $\begin{array}{l}\text { Group } 2 \text { (healthy } \\
\text { younger term) }(n=74)\end{array}$ & $\begin{array}{l}\text { Group } 3 \text { (healthy } \\
\text { older term) }(n=58)\end{array}$ & $\begin{array}{l}\text { Group } 4 \text { (prior } \\
\text { wheezing) }(n=43)\end{array}$ \\
\hline Antimony $(\mu \mathrm{g} / \mathrm{l})$ & $0.28(0.19$ to 0.41$)$ & 0.05 (0.04 to 0.07$)$ & $0.08(0.05$ to 0.14$)$ & $0.12(0.06$ to 0.24$)$ \\
\hline No $(\%)$ of infants with antimony $<0.02$ & & & & \\
\hline $\begin{array}{c}\mu \mathrm{g} / 1^{\star} \\
\text { No }(\%) \text { of infants with antimony }>\end{array}$ & 0 & $5(7)$ & $6(10)$ & $3(7)$ \\
\hline $1.0 \mu \mathrm{g} / 1 \dagger$ & $3(12)$ & 0 & $2(3)$ & $3(7)$ \\
\hline Antimony/creatinine (ng/mg) & $2.25(1.49$ to 3.39$)$ & $0.48(0.36$ to 0.65$)$ & $0.40(0.25$ to 0.65$)$ & $0.68(0.37$ to 1.25$)$ \\
\hline Cotinine/creatinine ( $\mathrm{ng} / \mathrm{mg}$ ) & $1.51(0.37$ to 6.2$)$ & $60.0(46.5$ to 77.4$)$ & $46.7(35.1$ to 62.1$)$ & 61.7 (41.6 to 91.5$)$ \\
\hline
\end{tabular}

* Laboratory detection limit.

† Mean urinary antimony concentration for healthy adults. ${ }^{20}$

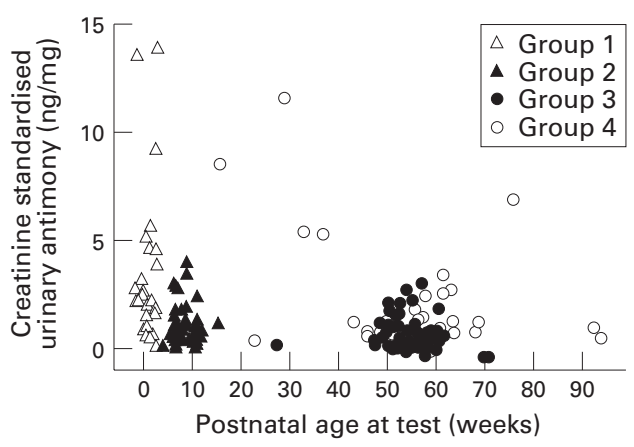

Figure 1 A scatterplot of creatinine standardised urinary antimony concentrations $(\mathrm{ng} / \mathrm{mg}$ ) against postnatal age (weeks) in infancy. Group 1: healthy preterm infants; group 2: healthy younger term infants; group 3: healthy older term infants; group 4: older infants with prior wheezing and lower respiratory tract illness.

\section{Results}

Table 1 summarises the characteristics of infants included in each of the four groups. Infants in group 2 ranged in age from 5 to 13 weeks, while those in groups 3 and 4 were approximately 1 year old and similar with respect to body weight and length at test. A similar and high proportion of infants in groups 2, 3, and 4 were exposed to maternal smoking during pregnancy and to tobacco smoke in the 24 hours before urine collection. A limited availability of spare urine from preterm infants whose mothers smoked during pregnancy resulted in a relatively low proportion of samples from such infants in group 1.

Urinary antimony concentrations were unrelated to the duration of frozen storage before assay (data not shown). Absolute antimony levels, unadjusted for renal function, were highest in preterm infants, below the laboratory detection limit of $0.02 \mu \mathrm{g} / \mathrm{l}$ in up to $10 \%$ of the term infants, and above $1 \mu \mathrm{g} / \mathrm{l}$ (the reference value reported for UK populations ${ }^{20}$ ) in $12 \%$ of healthy preterm infants and $7 \%$ of those with prior LRI with wheeze (table 2). After adjustment for renal function, the largest source of variation in creatinine standardised antimony values was due to between infant differences, which accounted for approximately three quarters of the total variability. Differences due to aliquot type were relatively minor and contributed only one tenth of this amount. Creatinine standardised urinary antimony was not associated with postnatal age; however, the highest levels were found in preterm infants and those with prior LRI with wheeze (fig 1; table 2). There was no statistically significant within-infant change in creatinine standardised urinary antimony levels for the 53 healthy term infants (18 with wheezing) for whom paired measurements at approximately 8 and 56 weeks of age were available (mean within infant
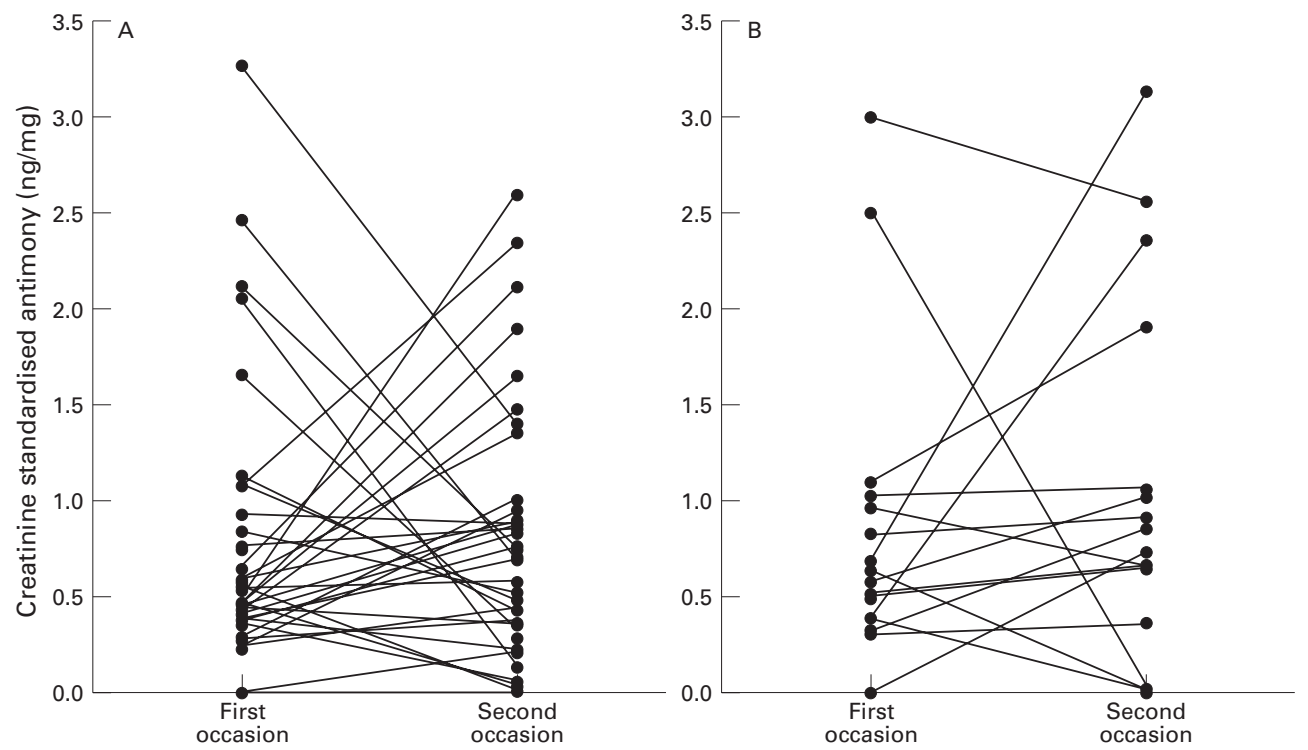

Figure 2 Within infant changes in creatinine standardised antimony concentrations ( $\mathrm{ng} / \mathrm{mg}$ ) measured on the first occasion at a mean age of 8 weeks and on the second occasion at a mean age of 56 weeks. (A): healthy infants without prior wheezing on either occasion; (B): healthy infants with wheezing before the second occasion. 


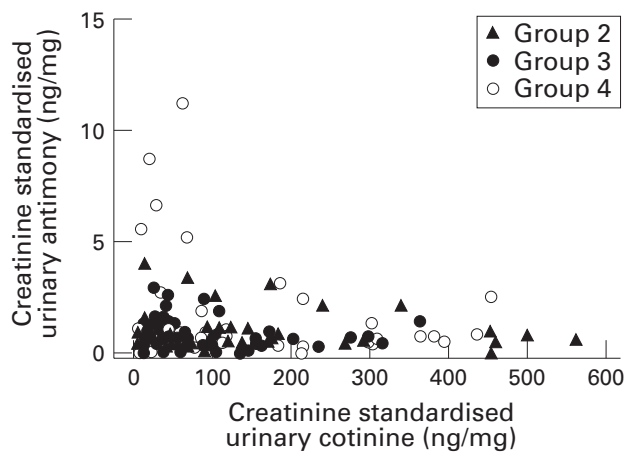

Figure 3 Scatterplot of creatinine standardised antimony and cotinine concentrations (both as $\mathrm{ng} / \mathrm{mg}$ ) in term infants. Groups as for legend to fig 1.

difference (result on second occasion minus that on first occasion) $0.12 \mathrm{ng}$ antimony/mg creatinine; $95 \% \mathrm{CI}-0.16$ to $0.4 ; \mathrm{p}=0.4$; fig 2 ).

Creatinine standardised urinary cotinine concentrations were lowest in the preterm infants (group 1), none of whom had been exposed to any tobacco smoke postnatally at the time of urine collection and only three of whom had had any prenatal exposure. In the healthy term infants and those with prior wheeze, postnatal exposure to tobacco smoke (as assessed by creatinine standardised urinary cotinine levels) was not positively related to creatinine standardised urinary antimony (fig 3).

\section{Discussion}

The findings of this study suggest that antimony may be detected, albeit in very low concentrations, in the urine of the majority of infants and very young children during the first two years of life. Byard and colleagues have stressed the risk of sample contamination in trace metal analysis. ${ }^{21}$ Although the urine analysed in this study was originally collected for cotinine assay, the antimony levels found are unlikely to reflect exogenous contamination since the urine collection protocol involved a stringent no-touch technique and the prior in vitro study indicated that there was no significant leaching of antimony from the bags, syringes, and tubes used to collect and store the urine. The lack of correlation between urinary antimony concentrations and duration of storage before assay suggested that leaching or deposition of antimony during frozen storage was unlikely. Contamination from prior sampling of the specimen was also unlikely since the variation due to aliquot type-that is, whether the specimen had been previously thawed, sampled, and refrozen, was minor relative to that due to between infant differences. Stringent laboratory quality control procedures were employed to minimise sources of variation due to measurement error, and a high level of agreement was obtained for the repeated measurements, which were undertaken on more than half of the samples.

To our knowledge, urinary antimony levels in infancy have not been reported previously for UK or other populations. ${ }^{22}$ The relevance of the levels found to health in infancy is uncertain, although it is unlikely that the levels of urinary antimony being excreted in this sample of infants reflect clinically important exposure since all infants were healthy and free of symptoms at the time of testing. Furthermore, inductively coupled plasma mass spectroscopy is extremely sensitive and measures minute concentrations of antimony, down to one thousandth of a part per billion or 0.001 $\mu \mathrm{g} / \mathrm{l}$. Low levels of antimony have been reported in the urine of adults who are not occupationally exposed. ${ }^{1320}{ }^{22}$ Bencze and Barchet reported that antimony was undetectable in the urine of $90 \%$ of occupationally unexposed individuals ${ }^{13}$; however, this was based on the less sensitive technique of hydride atomic absorption spectrometry with a reported detection limit of $0.5 \mu \mathrm{g} / \mathrm{l}$. By applying this detection limit to the current study, antimony would be considered undetectable in a similar proportion of samples, since $182(90.5 \%)$ of the 201 samples tested had absolute antimony levels less than $0.5 \mu \mathrm{g} / \mathrm{l}$. Between 3 and $12 \%$ of infants in this study had urinary levels greater than the reference value of $1 \mu \mathrm{g} / 1$ proposed for the UK population by Hamilton and colleagues. ${ }^{20}$ However, direct comparison with absolute values reported in adults may be misleading as renal function in neonates and young infants is relatively poor. Creatinine standardised values have not been reported in occupationally unexposed adults; however, urinary levels in lead battery production workers have been reported to range from 2.8 to 23.4 $\mu \mathrm{g} / \mathrm{g}$ creatinine and to correlate closely with exposure to atmospheric antimony. ${ }^{14}$

The opportunities for environmental exposure to antimony are probably greater than previously appreciated, since antimony is used in a wide range of industrial processes, including the manufacture of metal alloys, batteries, fireworks, and textile pigments. ${ }^{22}$ Antimony is present in various foods, notably sea water fish, ${ }^{13}$ is present in low concentrations in tap water, particularly in soft water areas, ${ }^{22}$ and is suspended as particulates in the atmosphere, principally from combustion of fossil fuels. ${ }^{22}$ Tobacco smoking is considered to be a potentially important environmental source. ${ }^{13} \mathrm{Al}-$ though plasma and urine concentrations of antimony have not been measured in smokers and non-smokers, the former are considered to be more strongly exposed in view of the estimated $20 \%$ retention of antimony after tobacco smoke inhalation and the relatively high concentrations found in tobacco. ${ }^{11} 1322$ The low proportion of urine samples from preterm infants exposed to tobacco smoke did not reflect prevalence of maternal smoking in this population, which was in fact higher than that amongst the other groups, ${ }^{23}$ but rather the difficulty in obtaining sufficient quantities of first urine samples for duplicate analyses. By chance this resulted in a very few samples from preterm infants of smoking mothers being available for antimony analysis. By contrast, a high proportion of the term infants included in the current study were exposed to significant amounts of tobacco smoke within the 24 hours before urine collection, as confirmed by the finding of cotinine levels in the range seen 
among active smokers. Despite this, no association was found between urinary concentrations of antimony (with a presumed half life of four days) and cotinine (with a half life of 24-48 hours). This suggests that passive exposure to tobacco smoke is unlikely to be an important source of environmental exposure to antimony in infancy.

In the current study, urinary antimony was not associated with postnatal age in term infants. In particular, levels were low or undetectable between 5 and 13 weeks of age, the peak age for death from sudden infant death syndrome. Information on mattress type and use of plastic mattress covers was not collected during these studies; however, urine samples were all collected after 1988, when many manufacturers increased the amount of antimony added to plastic mattress covers. ${ }^{11}$ Although urinary levels are unlikely to reflect cumulative exposure, there was no evidence of increasing or decreasing urinary levels with increasing age in the term infants with urine specimens available for two occasions. Despite the lower than anticipated exposure to maternal smoking during pregnancy among the preterm infants, ${ }^{23}$ antimony levels in this group were higher than those observed in older healthy term infants. This may reflect prematurity or fetal assimilation of antimony, since urine was collected within the first 24 hours of life from preterm infants. Further analysis of urine samples collected at this age from both term and preterm infants is required to distinguish between the effects of gestational and postnatal age at testing.

\section{Conclusion}

This study has confirmed that it is possible to detect antimony in the urine of healthy infants in the first two years of life. However, the concentrations found were very low, consistent with levels reported for non-occupationally exposed adults, and of uncertain relevance to health. Although higher absolute and creatinine standardised levels were found in urine collected from preterm infants in the first 24 hours of life, further research is needed to determine whether similar values would also be found in full term infants immediately after birth. Although tobacco contains significant concentrations of antimony, the findings of this study suggest that tobacco smoke is unlikely to be an important source of environmental exposure to antimony during infancy and early childhood.

We are grateful to the families and infants who participated in the studies reported here; to Margaret Fletcher, Isobel Dundas,
Ah Fong Hoo, and the midwives at the special care baby unit at the Homerton Hospital for their help in collecting urine samples; to Ivan House at New Cross Hospital for preparing matrix matched antimony standards; to Colin Feyerabend of the Nicotine Laboratory at New Cross Hospital for performing urinary cotinine assays; to Christine Sieniawska for analysis of antimony in urine. This study was supported by the Foundation for the Study of Infant Death (Grant No 199). CD is supported by the Wellcome Trust, LP by the Dunhill Medical Trust, and JS by Portex Ltd.

1 Richardson BA. Cot mattress biodeterioration and SIDS. Lancet 1990;335:670.

2 Richardson BA. Sudden infant death syndrome: a possible primary cause. f Forensic Sci Soc 1994;34:199-204.

3 Anonymous. SIDS theory: from hype to reality [editorial]. Lancet 1995;346:1503.

4 De Wolff FA. Antimony and health: incriminating stibine in the sudden infant death syndrome is difficult on current evidence. BMF 1995;310:1216-7.

5 Warnock DW, Delves HT, Campbell CK, et al. Toxic gas generation from plastic mattresses and sudden infant death syndrome. Lancet 1995;346:1516-20.

6 Gates PN, Pridham JB, Webber JA. Sudden infant death syndrome and volatile antimony compounds. Lancet 1995; 345:386-7.

7 Thompson M, Faull JL. Do microbiota cause emission of stibine from cot mattresses? Lancet 1995;346:1557-8.

8 Mitchell EA, Scragg L, Clements M. Cot mattresses and sudden infant death syndrome. Lancet 1995;345:1045-6.

9 Blair P, Fleming P, Bensley D, Smith I, Bacon C, Taylor E. Plastic mattresses and sudden infant death syndrome. Lancet 1995;345:720.

10 Bell SA, Cole M. Cot mattresses and sudden infant death syndrome. Lancet 1995;345:1046.

11 Fleming PJ, Cooke M, Chantler SM, Golding J. Fire retardants, biocides, plasticisers, and sudden infant deaths. BMF 994;309:1594-6.

12 Grandjean P. Health significance of metals. In: Last JM, Wallace RB, eds. Public health and preventive medicine. East Norwalk, CT: Prentice-Hall International, 1992:381-401.

13 Bencze K, Barchet R. Antimony. In: Angerer J, Schaller KH, eds. Analyses of hazardous substances in biological material. Methods for biological monitoring. Weinheim: Deutsche Forschungsgemeinschaft, 1988:31-45.

14 Kentner M, Leinemann M, Schaller KH, Weltle D, Lehnert $\mathrm{G}$. External and internal antimony exposure in starter battery production. Int Arch Occup Environ Health 1995;67: tery product

15 Dezateux CA, Stocks J, Dundas I, Jackson EA, Fletcher ME. The relationship between $t_{\mathrm{PTFF}}: \mathrm{t}_{\mathrm{E}}$ and specific airways conductance in infancy. Pediatr Pulmonol 1994;18:299-307.

16 Dundas I, Dezateux CA, Fletcher ME, Jackson EA, Stocks J. Comparison of single-breath and plethysmographic measurements of resistance in infancy. Am $\mathcal{f}$ Respir Crit Care Med 1995;151:1451-8.

17 Stocks J, Dezateux CA, Jackson EA, Hoo A, Costeloe KL, Wade AM. Analysis of tidal breathing parameters in infancy: how variable is $\mathrm{t}_{\mathrm{PTEF}}: \mathrm{t}_{\mathrm{E}}$ ? Am $\mathcal{F}$ Respir Crit Care Med 1994:150:1347-54.

18 Jarvis MJ, Tunstall-Pedoe H, Feyerabend C, Vesey C, Saloojee Y. Comparison of tests used to distinguish smokers from nonsmokers. Am F Public Health 1987;77:1435-8.

19 Gaultier C, Fletcher M, Beardsmore C, Motoyama E, Stocks J. Measurement conditions. In: Stocks J, Sly PD, Tepper RS, Morgan WJ, eds. Infant respiratory function testing. New York: John Wiley, 1996:29-44.

20 Hamilton EI, Sabbioni E, Van der Venne MT. Element reference values in tissues from inhabitants of the European Community. VI. Review of elements in blood, plasma and
urine and a critical evaluation of reference values for the urine and a critical evaluation of reference values for the United

21 Byard RW, Palmer L, Towsty A. Antimony detected in necropsy tissues may derive from contaminated formalin. Lancet 1995;346:1633-4.

22 United States Environmental Protection Agency. Health and environmental effects profile for antimony oxides. Cincinnati, Ohio: EPA, 1985. (Report No EPA/600/X-85/271.)

23 Stocks J, Dezateux C, Hoo AF, Rabbette PS, Costeloe K, Wade A. Delayed maturation of Hering Breuer inflation reflex activity in preterm infants. Am $\mathcal{F}$ Respir Crit Care Med 1996;154:1411-7. 